\title{
Curator and Critic: Role of the Assessor in Aesthetic Fields
}

\author{
Rachael Jacobs \\ Correspondence: Rachael Jacobs, School of Education, Australian Catholic University, Virginia, QLD, 4006, \\ Australia. Tel: 61-7-3623-7219. E-mail: rachael.jacobs@acu.edu.au
}

Received: November 2, 2012 Accepted: November 21, 2012 Online Published: November 28, 2012

doi:10.5539/hes.v2n4p114 URL: http://dx.doi.org/10.5539/hes.v2n4p114

\begin{abstract}
Assessment in aesthetic fields presents a myriad of challenges in the higher education environment. This paper uses a metaphorical representation to explore the role of assessors within aesthetic assessment settings in higher education. It begins with a discussion of aesthetic fields and an exploration of the role of assessment in this area. Following this, the relationship between teachers and learners in aesthetic assessment settings is explored, as are some of the tensions that accompany assessment in aesthetic fields. This paper reports on a narrative and ethnographic study that explores the role of assessors in the context of aesthetically rich assessment tasks. The study, which uses five participants teaching in higher education settings, arrives at a metaphor which likens the assessors' role to that of an artistic curator or art critic. The students' place within that metaphor is also explored. Finally, conclusions are drawn about the nature of assessment in aesthetic fields and areas for further investigation identified.
\end{abstract}

Keywords: aesthetic education, assessment, aesthetic assessment, higher education

\section{Introduction}

After you have introduced 'the problem and have developed the background material, explain your approach to solving the problem. In empirical studies, this usually involves stating your hypotheses or specific question and describing how these were derived from theory or are logically connected to previous data and argumentation. Clearly develop the rationale for each. Also, if you have some hypotheses or questions that are central to your purpose and others that are secondary or exploratory, state this prioritization. Explain how the research design permits the inferences needed to examine the hypothesis or provide estimates in answer to the question. Education can be an effective vehicle for the development of inter and intrapersonal skills, social and cultural action, self-expression and aesthetic awareness (Jacobs, 2009). The inclusion of 'aesthetic awareness' within this collection may be surprising to some. Aesthetic awareness is both a process and a product that allows learning to become aesthetically knowledgeable, or allows the learner to be open to engaging in aesthetic experiences. However, assessment in aesthetic fields presents a myriad of challenges in the higher education environment. This paper uses a metaphorical representation to explore the role of assessors in aesthetic assessment settings in higher education. To begin, a discussion of aesthetic fields is necessary, as is an exploration of the role of assessment in this area. The relationship between teachers and learners in aesthetic assessment settings is explored, as are some of the tensions that accompany assessment in aesthetic fields. The paper then explores a narrative and ethnographic study aesthetically rich assessment tasks using the voices of the educators who facilitate them. The study arrives a metaphor which likens the assessor's role to that of an artistic curator or art critic and explores the students' place within that metaphor. Finally, a summary of the paper points to areas for possible further investigation.

\section{Aesthetic Learning}

The inclusion of aesthetic understandings in education has long been advocated for. Dewey (1934) advocated for conscious involvement with aesthetics making a differentiation between 'aesthetic' and 'everyday' experiences. Eisner (1985) also states that aesthetic awareness provides an important lens on experience, a way of seeing that transcends the instrumental and disciplinary approaches where we are able to "learn from aesthetically rendered lives what words, paradoxically, can never say" (p. 35). It is not the intention of this paper to engage in a debate on the definition of aesthetics, as can be explored in numerous other literature (for example, Hekkert \& Leder, 2007; Donoghue, 2003; Sternberg, Kaufman, \& Pretz, 2002; Greene, 1999 to name a few) and this research acknowledges the many conceptions of aesthetic education that also exist (Peters, Marginson and Murphy 2009; Gale, 2005; Smith \& Simpson, 1991). However, it is necessary for this paper to identify what 'aesthetic fields' are, or what aesthetic assessment entails. 
Aesthetic education involves the explicit teaching of skills, knowledge and understandings that enhance the aesthetic experience. Aesthetic awareness can be heightened through aesthetic education, where students engage in expressive experiences in which sentimental interpretations and emotional responses are accessed. According to Dewey (1934), the three main components that constitute having an aesthetic experience are emotion, expression, and consummation. The dimensions of sentiency are also communicated and realised through these processes (Greene, 1991).

Drawing on the aforementioned sections of literature, aesthetic fields in higher education are ones in which students are explicitly taught skills, knowledge and understandings that enhance the aesthetic experience. These usually use expressive processes and emotional responses. These qualities often manifest themselves in highly creative and analytical work that contributes to our way of seeing (Greene, 1995). Gale (2005) adds that imagination and feeling can also be accessed - as can the metaphysical construction of alternative realities ( $\mathrm{O}^{\prime}$ Toole, 1997) - as perceptibility is explored.

However, the inclusion of aesthetic modes of thinking is somewhat at odds with the traditional structure of higher education. Rational and functional thought processes are more commonly privileged in western education systems, and aesthetic values are often absent in discussions of learning and curriculum. Academia is notoriously left-brained, and more accustomed to logical thinking modes, which are easily subjected to measurement. For this reason aesthetic learning can strike some as academically 'soft' or less rigorous than other modes of learning. Sadly, aesthetic appreciation also carries common perceptions of highly ethereal qualities that are abstract in nature or often associated with high culture (Ross, Randor, Mitchell, and Bierton, 1993). The importance of aesthetic literacy in the curriculum is further diminished when the aesthetic response is perceived as a private and feelingful reflection.

It is preferable to consider aesthetic awareness as a mode of cognition, a process, or a way of knowing, as these can be more easily understood by tertiary educators and administrators alike. When referring to aesthetic learning, Gale (2005) discards the fanciful language used by other writers, and illustrates the concept in terms of outcomes, describing what we can hope to see from students who are engaging aesthetically. These include analysis of aesthetic elements; development of personal and critical response through judgement and evaluative tools; appreciation of different cultures, values and contexts; understanding of disciplinary perspectives that inform the aesthetic; an active pursuit of aesthetic engagement; and an ability to articulate aesthetic processes. These outcomes have clear learning processes embedded in them. Aesthetic learning can take place in a myriad of disciplines (Jacobs, 2011), however its assessment is usually confined to fields where aesthetic thinking is regularly accessed and aesthetic language is commonly used. These fields will be discussed further within the section describing the participants in this study.

\section{Assessment in Aesthetic Fields}

Assessment is a critical component of the higher education learning environment. Like other modes of cognition, aesthetic learning can be assessed, although this concept is somewhat controversial. Like concepts such as 'creativity', aesthetic learning is not easily defined and therefore can be difficult to assess (Hanley, 2003). Traditionally, assessment practices in academia mostly conformed to the reductive tendency of non-aesthetic engagement, by pre-determining the knowledge of which the pupil would show evidence. This style of assessment continues to exist and has its own purposes today - the student selects responses from their experience in order to fit the function of the question that they are asked (Ross et al., 1993). Eisner (1998), writing about the aesthetic field of arts education, describes the tension that exists when considering the dichotomy of traditional testing and artistic processes.

"Testing aspires for all a set of common correct responses; in the arts, idiosyncratic responses are prized. Testing typically focuses on pieces or segments of information; artistic work emphasizes wholes and configurations. Testing emphasizes the acquisition of products produced by others; the arts emphasize content growing out of one's personal experiences, especially those having to do with matters of feeling. Such matters of emphasis are so fundamental that it seems as though testing and the arts reside in different worlds" (pg. 2)

It is worth nothing that since the time of Eisner's statement, the assessment landscape has shifted, and several styles of assessment are now acceptable in higher education settings. Recent literature highlights the benefits of assessment within aesthetic fields and attests to the high degree of integrity with which aesthetic learning is able to be assessed (Colwell, 2003; Hanley, 2003; Pistone, 2000; Willoughby, Feifs, Baenen, and Grimes, 1995). Students are required to synthesise their aesthetic understanding and formulate a product that can successfully respond to the task requirements. This can be a complex task, as reported by Taylor (2006) who states that "our students will 
be baffled, at times, and be thrown into states of disequilibria, and they will be frustrated by nonlinear and abstract artforms, where meanings are not immediately apparent..." (p. xx). However this is not a reason for not assessing in aesthetic fields, in fact, Taylor celebrates these complexities as the "hallmark" (p. xxi) of the aesthetic curriculum. Willoughby et al. (1995) similarly suggest that assessment is part of the solution to these challenges, explaining that assessment helps to objectively share the benefits of aesthetic learning with others.

The term 'objective' is interesting here, and worthy of further discussion. Often aesthetic learning conjures the notion of 'subjectivity' which can be off-putting in an assessment climate which is generally objectivity-focussed or at the very least, objectivity-seeking. This, of course, runs contrary to the nature of education, as O' Toole, Stinson and Moore (2009) remind us, "Knowledge and learning are of course never objective nor value-neutral, much though ultraconservative groups and politicians might wish them to be seen as such" (p. 108). Academic literature on aesthetic learning contains a myriad of views on subjective and objective judgement. Jackson (2006) argues that, "it should be possible to separate subjective judgements of creativity from judgements of technical goodness and from judgements of aesthetic appeal" (p.169). Harris (2008) is similarly objectivity-focused in her recommendations. However, Tomlinson (2001) argues for a "healthy balance" between subjective and objective types of performance assessment to provide the most "individually sensitive, accurate, and comprehensive evidence" of student learning (p. 15). Misson (1996) adds that embracing aesthetic learning as a site for constructing subjectivity will facilitate a nexus of intelligence and emotion. "Thought is charged with feeling, while feeling is refined and strengthened by thought" (p. 11).

\section{Relationship between Teacher and Learner in Aesthetic Assessment Environments}

The relationship between teacher and student takes on an interesting dynamic in the aesthetic assessment process, which Bird (2006) describes as "intense" (p. 80). Some styles of assessment may require teachers to have little or no contact with the students' work until submission, whilst other tasks may require the teacher to be involved in the development of the aesthetic response. Depending on the task, teachers can be involved in directing their students; they may assist in the refining process, and at times they challenge the aesthetic content of the student work. For example, in performance art fields Kempe (2000) believes that the success of student devised work relies on the teacher having developed independence in their students so they are able to collaborate with each other in performance making, without direct leadership by the teacher. Whilst Kempe was referring to secondary learning environments, he still raises a pertinent question: Are teachers who facilitate aesthetic tasks personally involved in their students' work? In the context of this paper, we must ponder what the consequences of this question are with regard to assessment. Harris (2008) adds that care must be taken if the assessment response has had a teacher's input, so that the aestheticism being assessed is not just an execution of ideas under guidance.

\section{Methodology: Developing the Metaphorical Representation}

The study that led to the development of a metaphorical representation of teachers and learners in aesthetic fields used narrative inquiry and ethnographic methods. Narrative research is highly linked to the context and allows for suitably complex issues to be explored in a manner that can provide paths towards outcomes and informed recommendations. Clandinin and Connelly (2000) explain narrative inquiry as a way of understanding experience through lived and told stories, which is highly relevant when discussing aesthetic matters. Narrative inquiry is the study of experience as story (Connelly \& Clandinin, 2006) and within the field of education it can help us negotiate complexities of the setting by grounding teachers' practices in experience (Parker, Pushor \& Kitchen, 2011). Narrative inquiry tools are advantageous for this study as they allow experiences to reflect the distinctive knowledge, based on the perceptions of the narrator, whilst encouraging the construction of meaning by participants in the context of their own experiences (Benson, 2005; Czarniawska-Joerges, 2004). Importantly to this study which involves inquiry into multiple discipline areas, narrative inquiry enables us to understand issues from multiple perspectives, allowing both the participant and researcher to identify and implement strategies for addressing those issues (Larson, 1997).

In an effort to ground this study in aesthetic settings and also illuminate the aesthetic facets of the assessment tasks that would be discussed in the interviews, this study used participant observation combined with ethnographic journaling. Participant observation was used to focus on the research volunteers in their everyday settings, with particular attention given to the way they make meaning in those settings (Anderson-Levitt, 2006). Participants were observed facilitating the aesthetically focussed assessment tasks that would be discussed in the interviews. The researcher kept an ethnographic journal in which observations were notated. The use of the assessment tasks as ethnographic artefacts also aimed to compliment the aesthetic nature of the field, as experiencing moments of aestheticism, tension and crisis would provide further opportunities to gain an understanding of aesthetic assessment experiences. 
Five tertiary educators that teach and assess aesthetic learning across four institutions in Queensland (Australia) were participants in the study. The participants were selected using critical base sampling to interview "those that can make a point quite dramatically or are, for some reason, particularly important in the scheme of things" (Patton, 1990, p. 174). In keeping with the literature explored in this paper, participants were identified as professionals who taught in units that explicitly addressed skills, knowledge and understandings that enhance the aesthetic experience. The participants also set assessment tasks that used expressive processes and emotional responses. Participants were contacted then responded positively to the invitation to be involved in the research. A pre-interview was conducted to screen each participant in which they were asked to describe their aesthetic learning and assessment processes. Once it was determined that they were suitable for the study they were engaged in a semi-structured interview where they were invited to tell stories about their practices. The first and only call for participants generated responses from a range of discipline areas including the arts, literature and philosophy. The participants, their discipline areas and assessment tasks observed were:

\section{Participant 1: Philosophy lecturer conducting a creative writing task}

Participant 2: Drama lecturer conducting a theatre performance task of self-devised work

Participant 3: Visual Art lecturer conducting assessment of student art works

Participant 4: English literature lecturer conducting a poetry writing task

Participant 5: Music lecturer conducting a performance assessment task of students' own compositions

It must be noted that this study does not presume that this is a definitive list of disciplines or styles of assessment that use aesthetic teaching, learning and assessment, and the researcher acknowledges that there are many other fields that use and value aesthetic learning. These participants are, however, able to highlight aesthetic learning and assessment strategies in higher education. The small sample of participants does not pretend to be a representative sample of aesthetic educators. However, within the boundaries of the research topic, the narrative inquiry method enables relevant themes to be exposed whilst emphasising the importance of 'story-truth' (O' Brien, 1990) in examinations of the field.

In individual semi-structured interviews participants were asked questions, surrounding three key areas; 1) Participants' descriptions of aesthetic teaching and learning in their units, 2) Their assessment processes that access aesthetic learning and 3) Commentary on the strengths and challenges associated with aesthetic assessment in their learning programs. The data collection and analysis ran together, as suggested by Wiersma and Jurs (2005). The process is highly suitable for narrative inquiry, as data must be synthesised into an explanation that requires recursive and reflexive action from the data to the emerging narratives (Polkinghorne, 1995).

The data collection and analysis took place through a modified use of Chinyowa's (2006) methodological process, which is highly suitable for research in aesthetic fields. The process involved the phases of framing; capturing; bracketing; crystallising and interpreting. The interviews were the framing and capturing phases. They were followed by a process involving review and organisation of statements (the bracketing phase), after which a process of coding and categorisation of themes (the crystallising and interpreting phases) was used. Finally, a reflexive element of analysis was employed; participants were contacted intermittently to clarify issues and elaborate on their responses on matters that emerged through data interpretation. The analysis of transcripts and qualitative contextual data looked across all the participants as well as at each individual, to compare and contrast at every stage of the scheduled interviews, similar issues that were 'lived' by these participants. By framing the issues as thematic categories then grouping the questions within each of these categories, the study was able to create summaries for interpreting how each participant similarly or differently addressed the research questions as 'lived experiences'.

The inclusion of aesthetic understandings in education has long been advocated for. Dewey (1934) advocated for conscious involvement with aesthetics making a differentiation between 'aesthetic' and 'everyday' experiences. Eisner (1985) also states that aesthetic awareness provides an important lens on experience, a way of seeing that transcends the instrumental and disciplinary approaches where we are able to "learn from aesthetically rendered lives what words, paradoxically, can never say" (p. 35). It is not the intention of this paper to engage in a debate on the definition of aesthetics, as can be explored in numerous other literature (for example, Hekkert \& Leder, 2007; Donoghue, 2003; Sternberg, Kaufman, \& Pretz, 2002; Greene, 1999 to name a few) and this research acknowledges the many conceptions of aesthetic education that also exist (Peters, Marginson and Murphy 2009; Gale, 2005; Smith \& Simpson, 1991). However, it is necessary for this paper to identify what 'aesthetic fields' are, or what aesthetic assessment entails. 


\section{A Metaphorical Representation of Teachers and Learners in Aesthetic Fields}

During the interviews all participants made reference to aesthetic experiences outside of the university setting that relate to the teaching and learning experiences they facilitate. Some participants made comparisons between the work that takes place within their units and aesthetic fields that were possible sites for students' future vocational or professional aspirations. For example, Participant 2, a Drama educator, drew parallels between their lessons and the work of playwrights and directors; Participant 3, a Visual Arts lecturer, noted the work of art curators and critics. An extract from Participant 4's interview illustrates one of the ways in which participants arrived at these parallels in their narratives:

Participant 4: What we do is important, not because they're going to be poets but I want them to understand the work of writers and critics and the function of literature in our society. I'm not preparing them for the workforce, but I am preparing them to be consumers of writers' works. That's why I often make comparisons with what we do to the roles out there in the real world.

Participant 4's reference to 'the real world' is interesting. They have recognition of the university setting as an environment rich in theoretical understandings as well as understanding that university often prepares students for vocational or professional participation. Other participants made similar comments, some of which elaborated on tensions and challenges that exist when applying aesthetic learning to environments outside of their learning environment. As a result of the connections and comparisons made by participants, I decided to develop a metaphor that combined their perspectives and engaged their storied descriptions.

The participants described their roles facilitating aesthetic learning as multifaceted; to begin, they described themselves as having a direct role in dictating the aesthetic pathway that their learners would tread. This was particularly evident when they discussed their planning, the materials chosen for study and the focus of the assessment tasks they set. In other instances they described themselves as facilitators of learning that was more student centred. Their units would enable students to engage in their own pathway of research, imaginative work or creative tasks. Some participants felt that the assessment experience could be a bridge between these two facets, and several commented that each approach complimented the other.

Participant 5: There definitely needs to be some balance. I don't want them to just show me my work back to me. I want them to create their own composition, but within a structure. I need to teach them about all the devices and techniques they're learning about before they can go forward and create their own.

In response to these storied descriptions of participants' transient roles, the metaphor I developed centred around the participant as a curator or aesthetic experiences within their field. This section of the paper develops that metaphor as well as reflecting on its limitations. It extends the metaphor to discuss students as 'artists' who respond to the aesthetic demands made by the curator.

To begin, I will start with an exploration of the role of the curator in the wider world in an effort to help situate the metaphor. Curators operate in a range of fields and their roles can be highly varied. They can be required to research new mediums of work or develop intimate knowledge of heritage works. Curators are passionate advocates of their fields. Drawing from the world of artistic curation, Eeds and Peterson (1991) state that they "know art, collect it, care for it and delight in sharing it with others, helping them to see it in ways they may not have discovered if left on their own." (p.118). This description has a high level of congruence with the participants' narratives when they described the ways they engaged the content or subject matter. And in a similar way to curators, the participants described ways they worked with their students to facilitate work that was intellectually, emotionally, imaginatively and sometimes, physically engaging with their audience.

Through the participants' narratives, it was also clear that they facilitate learning experiences within the context of a learning program and make influential decisions about what styles of responses are to be produced for the purpose of assessment. As one participant stated:

Participant 3: I' $m$ also really mindful that I' $m$ dictating the styles of art we're going to be looking at in the unit. And of course, that's influenced by my own knowledge and that will affect what students create for their assignments.

In a similar way, curators play an essential role in the development and preservation of artefacts in our society. In artistic fields they also make influential decisions about what aesthetic products are developed and consumed in that society. As the British noted gallery curator, Sylvester (1999) explains, "Art today is surrounded by explanation and contextualisation. It is curated" (para. 3). One of the central roles of the artistic curator is to recommend works, artefacts or artists for exhibition. They are responsible for organising exhibitions or 
performances, and along with that the necessary promotion of particular exhibitions or artists. In the interviews for the study participants highlight similarities and it becomes evident that they have subjected the higher education learning environment to curation. Like the curator, the participants were charged with organising the timing and nature of the 'exhibition' of student works, that being the assessment task. The participants in this study chose to curate using styles of assessment that they were drawn to out of either their own familiarity or interest. At times some teacher curators made assessment or programming decisions based on their assumptions of what would be of interest or advantageous to their student artists.

Through the process of assessment, the participants, which are described here as 'teacher curators', are firstly aiming for the students to grow in their aesthetic knowledge, skills and understandings. In some cases they are also developing an exhibition to be consumed by an audience. For example, Participant 2's assessment task is contributing to a Drama festival; Participant 4 is facilitating a live poetry reading. The following narratives tell us about their dual motivations to both grow students' understandings and curate an exhibition.

Participant 2: Well, it's not simply about this one task. While I want them to produce a comprehensive piece for this unit, I also want them to learn and grow as performers and this helps them learn and grow as people. But, as performers I want them to put on a great show that will attest to what they've learned.

Participant 4: The task I'm referring to is their poetry task, where they need to develop a piece then perform it as a reading or poetry slam or something like that. They need to understand the poetic dimensions of their own writing but also feel it when they perform, and that's going to be a great show, which, frankly, will encourage others to take this unit.

\section{Creating the Brief}

The interviews explored the way that participants went about planning assessment experiences. The process they described holds further parallels with the metaphor of the teacher as curator, more specifically, drawing on the curator's role in creating a 'brief'. A curator's brief aims to succinctly explain the aims, scope and boundaries of the project. It is the role of the curator or artistic board to create a brief that is ideally easy to read and addresses potential issues and questions that are likely to be raised by the artist. To this, the artist must respond accordingly in order to have their work exhibited. The artist responds with their interpretation of the brief's requirements, not by merely replicating the curator's instructions, but adding to it with imagination and innovation. The artist has the freedom to produce responses that are highly original and creative, which can include responses that the curator was not expecting. The responses can be divergent or tangential in a way that broadens the interpretation of the brief whilst responding to it.

So too, in the tertiary learning environment, a brief is created by the teacher curator, manifesting itself as the assessment task or the 'task sheet' as the participants referred to in their narratives. When designing the brief, the teacher curators in this study made decisions with regard to the aesthetic content and their complimentary parameters, such as time limits, number of student artists working on the project and so on. When discussing the development of their brief, several of the teacher curators emphasised their desire to be specific about their expectations, whilst leaving scope for the student artists to utilise their creativity. This aim is consistent with the literature that suggests that the assessment task should act as a starting point from which the students' aesthetic response should flow. Participant 1 elaborates on the ways the student is able to interpret, then respond to the brief.

Participant 1: I know the students see this task as just another essay, not very creative or aesthetic, but when I set the task sheet I see that as the beginning. It shouldn't tell them what to do, it points them in the direction of what to consider. I don't want my lecture notes regurgitated in essay form. I want them to really think, emotionally experience a bit of anguish, add their own ideas, express an opinion and emote. And they can write in a way that's full of feeling and passion. There. There's your aesthetic experience.

Participant 1's narrative also revealed the teacher curator forming a relationship between their own aesthetic expectations and what they perceived the students to be capable of producing. The teacher curator's expectations were quantified onto the marking criteria which accompanied the brief and this is where one of the tensions of the artistic process crystallised. The brief, or 'task reflected the aesthetic and educational agenda of the teacher curator. Concurrently, the accompanying marking criteria was directed at producing a quantifiable result rather than producing an aesthetic experience or product. That being said, there were several common dimensions between the brief and marking criteria; both contained aesthetic aims and emphasised the need for originality and innovation to dominate the student artists' response. However, the language used in the marking criteria was more technically 
descriptive, using specific terms that described the relevant skills and content being addressed, in comparison to the brief, which contained more of a general statement of the teacher curator's agenda. In response, the need to make the artistic brief and accompanying marking criteria accessible to students became a strong theme that emerged from the data. It is here that the teacher curator was seen to be using the language of the student artist in the hope of allowing them to access their own aesthetic interpretations to arrive at an understanding of the brief.

\section{The Student Artists' Response}

When discussing the responses that participants expected to see from their students, all reported that they wanted to see the students aesthetic learning actualized in the assessable product. A further extension of the metaphor sees the students as 'artists' who are responding to the brief which expects a response with an aesthetic dimension. The assessable work of the student artist is highly contextual as it is made for the purpose of responding to the teacher curators' brief. There are several tensions that emerge in this process. Firstly, it is interesting to investigate how much of the student artists' own aesthetic, style or interpretations are contained within their response to the brief. This issue raises great questions over the role of originality within the confines of the brief. The way that divergent responses are treated also comes into question. And finally the extent to which the teacher curator leads the aesthetic process is worthy of investigation.

Greenway (2003) suggests that the relationship between curator and artist should be one of mutual respect, support and even adventure. The teacher curators in this study indicated that many of the student artists were aiming to facilitate their own growth, whilst also aiming to be 'successful' in responding to the curator's artistic brief. Their definitions of success included passing the unit or assessment task, gaining positive feedback on their creative work, having their work proudly publicly displayed or even self satisfaction at having engaged in a challenging aesthetic process. The tasks that the participants described generally afforded the students a great deal of freedom, as they were able to plan, develop and execute their own aesthetic response.

\section{Teacher as Critic}

In the participants' narratives, a common tension emerged as they described the process by which they would make quantifiable judgements on students' aesthetic work. Several discussed the challenges they encountered when assessing aesthetic work that was the product of the students' independent interpretation of the brief. As Participant 3 explains:

Participant 3: I want them to interpret, and sometimes I give feedback on their work, so we're sort of collaborating. And they're really emotionally tied to their work. And I have to go and mark it. I feel like a bit of a downer when they don't get what they think they deserve.

At the time of the exhibition, or assessment, it became evident that the teacher curator has a shift in role. They become the critic, as they are required to assess the student artists' creations from an aesthetic perspective, as well as arrive at a grade or result which quantifies the student's achievement. This is a marked turning point in the teacher curator's role and a departure from the realities of curation in the professional world as the curator is often considered separate from the critic. Australian curator Daniel Thomas (1999) believes the curator needs to be impartial and separate from the critiquing process. He states "it would be unthinkable for an art-museum curator to be an art critic. It would be seen as an impossible conflict of interest" (p. 4). The 'conflict of interest' to which Thomas is referring mirrors the issues that are raised in this study over the preferences of the teacher curator and the extent to which student artists work with these preferences in order to gain favourable results. Participants' narratives showed some awareness of this quandary.

Participant 3: They certainly play the assessment game. They know what styles of art I am sympathetic to and what my views are on their choice of materials or whatever. And they can play that to get a good grade.

Having acknowledged the differences between the professional and tertiary environments in this regard, it must also be noted that some participants made comments which point to a strong intersection between the role of curator and critic.

Participant 3: But those opinions I have, it's because of the quality of the work. If I don't want them using prints, it's because they're not overly successful at it. Or because it's not going to work. So, I'm sympathetic to good work, really.

Participant 3's earlier use of the word 'game' is interesting. Orrell (2005) uses the metaphor of describing assessment as a 'game', and has written widely about students' understandings of what he refers to as the 'rules of the game'. As discussed in the literature, the use of assessment criteria mean that personal taste need not influence 
a student's drama assessment results, therefore some objectivity is present. However, the student artists are also taking into account the possible interpretations of the teacher curator and they are therefore addressing the subjective elements of the artistic process concurrently. Through Orrell's lens, the student artists have applied the rules of the game to their artistic process. However, the metaphor of the 'game' sits somewhat uncomfortably in a context where the teacher has acted in a collaborative and supportive role. Likening the student artists' awareness of the teacher curator's preferences to game playing somehow implies that they have used underhanded methods to discover a secret code that was shielded by the teacher until they are found out. When the student artists attempt to address the teacher curator's preferences, they are showing maturity in the way they are responding to the brief. The student artists are developing an awareness of the ways in which the outside world will interpret their aesthetic creations and they are adjusting their response to fit the purpose of the brief.

Once again, this mirrors the wider artistic world. It is often advised that artists engage in research to understand the persuasions of the curator before crafting their response. Scott-Murphy (2004) claims that it is possible to either subvert or find alternative ways of responding to the brief in a way that may prove to be surprisingly favourable... such as finding common interests between the artist and the curator. She suggests researching the orientation of the selection panel to ensure they are open to the artists' preferred style. The disposition of the curator which can influence the success of the artists' work holds much resemblance to the concept of the hidden curriculum (Margolis, Soldatenko, Acker \& Gair, 2001; Bergenhenegouwen, 1987; Cornbleth, 1983; Martin, 1983; Snyder 1971). The assessment environment in the aesthetic fields also subject to the hidden curriculum in which implicit and informal aspects of the curriculum are discovered through engaging in the learning environment. Like all environments, assessors in aesthetic fields will have expectations that are explicitly stated and other messages about what learning will be rewarded. However, aesthetic fields require both the learner and teacher to be open to learning possibilities that are outside of the teachers' expectations. For example, Scott-Murphy argues that there are numerous examples where artists have been successful in gaining tender or selection when working outside the scope of the original brief. In this study, working outside the brief is referred to as providing a divergent response. Participant 2 discusses the assessment of such responses and the way in which they can enhance the learning process.

Participant 2: It can happen that I'll get a theatrical response that I completely did not expect. And that's fine. In fact it makes me and the students go 'I never thought of viewing it that way'. That's the joy of Drama to me; no right and wrong answers and your perspective is being challenged the whole time. I'd actually love them to come of with original ideas that I haven't thought of before.

As discussed in the literature, in aesthetic realms divergent responses are permitted and in some cases, encouraged. However, the place of divergence within the confines of an aesthetic paradigm is of interest here as the role of originality and innovation is called into question. Another area for possible investigation is the extent to which students feel comfortable submitting a divergent response, knowing it will be summitavely assessed. Participant 5 reflects on the conundrum this presents for her particular task.

Participant 5: In many ways the students don't like to take risks with assessment. I want them to break out and try some really crazy compositions. And they'll get it wrong sometimes, but that fear of getting it wrong really paralyses them. To the point where they only want to get it right.

Participant 5's comment leads us to ponder the extent to which the act of assessment discourages divergence in aesthetic fields and this is an area for further research.

\section{Limitations of the Metaphor}

The metaphor of the teacher as curator, then critic, has been constructed from the participants' descriptions of their roles as the facilitator and assessor of aesthetic learning experiences. Having said this, there are several limitations and caveats that must be acknowledged when applying this metaphor. Firstly, there are some notable differences between the aims of teachers and the aims of curators. These can be reconciled, for example, when referring to visual art curation, Rendle-Short (1999), describes the role of the curator in a way that is highly synonymous with that of a teacher. "The role is more one of facilitation, collaboration and coordination between artist, audience and institution" (p. 15). Many of the teacher curators in this study were concurrently curating exhibitions and collaborating with students. But in wider society, the role of the curator is an acutely complex one that involves far more responsibilities than coordinating and mediating between parties. Sylvester (1999) argues that the contemporary art curator plays a "far grander" (para. 5) role in a way that uses their position in a powerful or even manipulative manner. He asserts that curators have the power to cultivate taste, powerbroke careers and, in instances, become the star of the exhibition themselves. He states "At its worst, the curator stands between us and the art" (para. 5). 
It can safely be said that very few tertiary educators are attempting to dramatically shift society's cultural identities or powerbroke students' careers. But the symbolism of the curator standing between the consumer and the art is very much a factor worthy of consideration in this study. Sections of this study that examined the teacher curator's aims showed that the participant brings with them several agendas when designing the assessment task or exhibition program. Like the curator, to a certain extent the participants in this study are able to filter, direct or even control the aesthetic products and the way they are consumed.

The term 'agenda' can have negative connotations when denoting one's desire to influence or manipulate a circumstance, and hints at these being carried out in an deceitful way. This use of the word in this study is not intended this way. Rather, it is referring to the teacher curator's set of goals for their assessment program, as well as the ideological and cultural background that influences the way they approach assessment. In wider artistic society the curator brings their own philosophies, understandings, artistic and cultural ideas to the role, and these ideas influence the artefacts that are exhibited or commissioned. Similarly, in this research, the curator's agenda is referring to the teacher curators' conscious or subconscious ideas on what student artists should be studying and producing.

Participant 5: For example, there's one task students are doing at the moment which is $20^{\text {th }}$ Century composition performances which is quite difficult. I' $m$ not trying to torture them, which I'm sure they think I am. But I want them to get a sense of the difference between performing and composing $20^{\text {th }}$ Century music, but I also want them to express more contemporary ideas through their music. They're so used to producing measured traditional stuff and I want them to break right out of that mould.

This explanation shows the teacher curator concurrently facilitating learning experiences while curating a task, based on their agenda. Once again, we can also see the hidden curriculum at play. The hidden curriculum and the concept of agenda are intertwined; the teacher curator does not explicitly teach the expectations and prepositions of their aesthetic understandings. Yet the student who is most attuned to these factors will be better equipped to academically succeed in the assessment task. To return to the issue of limitations, while there are some inconsistencies between the roles of teaching and curating, there are moments in the overall concept where conditions mirror each other. By drawing parallels the limitations can help to deepen our understanding of the assessment context in tertiary settings. Examination of the similarities between the curator's agenda and the hidden curriculum is one such example. Artists successfully negotiate curators' agendas, however, there is an argument that some students are disadvantaged in the face of the hidden curriculum (Anyon, 1980; Kentli, 2009). Looking to the world of the arts may allow for insights into ways that students can negotiate the hidden curriculum as well as broaden our thinking on tacit learning.

Returning to the issue of the assessor as critic, there are some limitations whereby the roles of critic and curator have significant differences. Mirroring the curator's world once again, critique is often a necessary part of the public process of curation. For example, in the world of the arts critique is often applied to commentary on a particular piece of art. When critique is given by a professional critic it is mostly made without regard to the artists' sentiments or disposition, therefore on occasions it can be particularly scathing. At other times it can contain accolades of praise. The purpose of such critique is to engage in a dialogue with the wider arts community about the perceived value of a contribution to the field. The critique is not created solely for the artist to absorb on an individual level. Rather, it informs the consumers and other critics about developments in the field. In contrast to this, the participants described their feedback to students as having a tone that was firstly informative, explaining the reasons for each of the criteria or standards of achievement being applied to the students' performance. They then provided justification for the final application of marks or grades to the work. Most importantly, participants stressed that all of their comments gave a summary of the ways in which the student could improve their future submissions. Participants' critique moved beyond commentary to act as a guide for students' aesthetic development. They also emphasised that a supportive tone was applied universally. As critics, participants were prepared and able to defend their critique, however it is evident the teacher never truly leaves the curator role, as their critique is focussed on developing learning.

Finally, there are some further limitations with regard to the practical application of the metaphor. The student artists are not expected to be experts or highly accomplished producers of aesthetic work. Rather, theirs is the role of the novice; the brief aims to appropriately challenge them whilst giving them scope to present their understandings of that which is being studied. Additionally, in the participants' units, engagement in assessment was compulsory, unlike a professional tendering process where only selected works are exhibited. At times in the artistic world, artists are called upon to help craft a performance season or exhibition. Artist consultations take 
place where their views are allowed to guide the curator's brief. In this research context, the student artists had no input into the brief, however it should be noted that there was data indicating the altering of the brief from year to year by the teacher curator based on their evaluations of its effectiveness. These evaluations most certainly take into account the student artists' response to the brief.

\section{Continuing the Conversation}

Participants' narratives showed some affinity with the role of the curator in the way that their agendas allowed them to create a brief to which the student artists would respond. Similarly, the students have entered an aesthetically focussed course of study with an understanding that they were expected to become student artists who would imagine, plan, create or perform an aesthetic response.

The questions of objectivity and subjectivity in the critique of artistic works are frequently discussed in both educational and professional contexts. As is discussed within academic literature there is a valid place for both, and the intersection of the two can be used to create informed judgments (Ross et al., 1993) about a student's assessment responses. Informed judgments are also a product of the teacher curator's agenda and the hidden curriculum, and to this student artists develop some awareness. The student artist often responds to both the artistic brief and the teacher curator's agenda concurrently in an effort to produce what they consider to be a successful response. This process need not stifle creativity or repel divergent responses. Divergence is able to be incorporated into the brief, by way of tailoring the assessment criteria in such a way that it can accommodate aesthetic modes of thinking.

The limitations that can be applied to this metaphor are a reminder that the assessment environment in higher education does not directly mirror the world of curation. However, these limitations point us to possible areas for the development of assessment practice in tertiary settings. For example, there is more scope for students' input into assessment to be accommodated or instances where students can collaborate on the planning of assessment in the same way that community consultations can help curators to plan their work. Understanding the differences between the curators' and critics' role can deepen understandings about the tensions that occur when teaching and assessing aesthetic learning. Reflexively, there may be some room for curators and critics to broaden their understanding of the nature of and purpose of feedback if they look to tertiary education settings for guidance.

Drawing a metaphor between teaching and learning in tertiary settings and the wider aesthetic community has the potential to deepen understandings, broaden thinking and point to future pathways for the development of assessment in aesthetic fields. Some possibilities for future research avenues include engaging curators in discussions which further compare and contrasts their role with educators. Another possibility is the facilitation of dialogue between curators and educators in an effort to provide insights into the aesthetic response as it is realized in students' or artists' creations.

The field of aesthetic education is intricate and nuanced, and when the dimension of assessment is included it becomes rich with tensions and challenges. As a reflection of the field itself, it is imperative that researchers and practitioners use creative and imaginative thinking to find solutions to these challenges, and the discussion of metaphors is one way to approach the dialogue. There are several limitations that apply, but those limitations are also reflective of the field itself; One of the joys of aesthetic learning is its subtly, ambiguousness, and its lack of definitive correct answers. Aestheticism often raises more questions than it answers, which in turn allows educators and learners to constantly philosophise, theorise and question their understandings. The tensions explored in this paper are not without their solutions, but like aestheticism itself, they require deep thinking and intense discussion. In conjunction with this, pathways to improvement can be found through creative approaches to considering the aesthetic world.

\section{References}

Anyon, J. (1980). Social class and the hidden curriculum of work. Journal of Education, 162(1), 67-92.

Benson, R. (2005). Using narrative enquiry to explore some implications of developments in educational technology for distance education. In T. Evans, P. Smith, \& E. Stacey (Eds.), Research in distance education, 6(4). $\quad$ Retrieved November $2, \quad 2008, \quad$ from http://www.deakin.edu.au/education/rads/conferences/publications/ride/2004/doc/4Benson.pdf

Bergenhenegouwen, G. (1987). Hidden curriculum in the university. Higher Education, 16, 535-543. http://dx.doi.org/10.1007/BF00128420

Bird, J. (2006). One-on-one: What is the role of the drama teacher in the process of teaching the solo performance? NJ (Drama Journal), 30(1). 79-89. 
Chinyowa, K. C. (2006). The ethnography of performance as a methodology in African theatre for development. NJ (Drama Australia Journal), 30(2), 83-92.

Clandinin, D. J., \& Connelly, F. M. (2000). Narrative inquiry: Experience and story in qualitative research. San Francisco: Jossey-Bass Publishers.

Colwell, R. (2003). The status of arts assessment: Examples from music. Arts Education Policy Review, 105(2), 19-29. http://dx.doi.org/10.1080/10632910309603457

Connelly, F. M., \& Clandinin, D. J. (2006). Narrative Inquiry. In J. L. Green, G. Camili, \& P. Elmore (Eds.), Handbook of complementary methods in education research (3rd ed., pp. 477-487). Mahwah, NJ: Lawrence Erlbaum.

Cornbleth, C. (1984) Beyond Hidden Curriculum?. Journal of Curriculum Studies, 16(1), 29-36. http://dx.doi.org/10.1080/0022027840160105

Czarniawska-Joerges, B. (2004). Narratives in social science research. Thousand Oaks, CA: Sage.

Department of Arts, Sport and Tourism. (2011). Interpreting a brief. Retrieved December 11, 2011, from http://www.publicart.ie/main/per-cent-for-art-and-commissioning/commissioning-process/artists-briefs/inter preting-a-brief/

Dewey, J. (1934). Art as experience. New York: The Berkeley Publishing Group.

Donoghue, D. (2003). Speaking of beauty. New Haven: Yale University Press.

Eeds, M., \& Peterson, R. (1991). Teacher as curator: Learning to talk about literature. The Reading Teacher, 45(2), $118-126$.

Eisner, E. (1985). Aesthetic modes of knowing. In Learning and Teaching the Ways of Knowing (pp. 23-25). Chicago: University of Chicago Press.

Eisner, E. (1998). The kind of schools we need: Personal essays. Portsmouth: Heinemann.

Gale, R. (2005). Aesthetic literacy and the "living of lyrical moments". Journal of Cognitive Affective Learning, 2(1), 1-9.

Greenaway, P. (2003). Getting Exhibited. Australia Council of the Arts website. Retrieved December 17, 2011, from http://www.australiacouncil.gov.au/resources/reports_and_publications/subjects/marketing/getting _exhibited

Greene, M. (1991). Aesthetic literacy. In R. A. Smith \& A. Simpson (Eds.), Aesthetics and arts education. Champain, Ill.: University of Illinois Press.

Greene, M. (1995). Releasing the imagination: Essays on education, the arts, and social change. San Francisco: Jossey-Bass.

Greene, M. (1999). Variations on a blue guitar: The Lincoln Center Institute lectures on aesthetic education. New York: Teachers College Press.

Hanley, B. (2003). Policy issues in arts assessment in Canada: "Let's Get Real". Arts Education Policy Review, 105, 33-37. http://dx.doi.org/10.1080/10632910309600750

Harris, J. (2008). Developing a Language for Assessing Creativity: A taxonomy to support student learning and assessment. Investigations in university teaching and learning, 5(1). Retrieved May 3, 2011, from http://www.londonmet.ac.uk/fms/MRSite/psd/hr/capd/investigations/vol5/INV\%205_013\%20-\%20Harris.p $\mathrm{df}$

Hekkert, P., \& Leder, H. (2007). Product aesthetics. In H. N. J. Schifferstein \& P. Hekkert (Eds.), Product experience. San Diego, CA: Elsevier Science Publishers.

Jackson, N. (Ed.). (2006). Developing creativity in higher education: An imaginative curriculum. Oxford: Routledge.

Jacobs, R. (2009). Measuring aesthetic development: A national dialogue. Journal of Artistic and Creative Education, 3(1), 75-96.

Jacobs, R. (2011). Aesthetic development in higher education: An interdisciplinary dialogue. Practice and Evidence of the Scholarship of Teaching and Learning in Higher Education, 6(3), 232-248.

Kempe, A. (2000). "So whose idea was that then?": Devising drama. In H. Nicholsen (Ed.), Teaching drama 11-18 
(pp. 64-76). New York: Continuum.

Kentli, F. D. (2009). Comparison of hidden curriculum theories. European Journal of Educational Studies, 1(2), 83-87.

Larson, C. L. (1997). Re-presenting the subject: Problems in personal narrative inquiry. Qualitative Studies in Education, 10(4), 455-470. http://dx.doi.org/10.1080/095183997237034

Margolis, E., Soldatenko, S., Acker, S., \& Gair, M. (2001). Peekaboo: Hiding and outing the curriculum. The Hidden Curriculum in Higher Education. New York, NY.: Routledge.

Martin, J. (1983). What should we do with a hidden durriculum when we find one?. In H. Giroux \& D. Purpel (Eds.), The Hidden Curriculum and Moral Education. Berkeley, California: McCutchan Publishing Corporation.

Misson, R. (1996). Dangerous lessons: Sexuality issues in the drama classroom. NADIE Journal, 20, 11-21.

O’ Brien, T. (1990). The things they carried. New York: Broadway Books.

O' Toole, J. (1997). Exciting Writing: Re-evaluating some practices in writing about drama and its research. Research in Drama Education: The Journal of Applied Theatre and Performance, 2(2), 185-191.

O’ Toole, J., Stinson, M., \& Moore, T. (2009). Drama and curriculum: A giant at the door. Springer: Fitzroy.

Orrell, J. (2005). Assessment Literacy: A Precursor to Improving the Quality of Assessment. Paper presented at the Evaluation and Assessment Conference.

Parker, D. C., Pushor, D., \& Kitchen, J. (2011). Narrative inquiry in teaching and teacher education. In J. Kitchen, D. C. Parker \& D. Pushor (Eds.), Advances in Research on Teaching, Vol. 13. Narrative Inquiries into Curriculum Making in Teacher Education (pp. 3-68). Bingley, UK.: Emerald Group Publishing Limited.

Patton, M. Q. (1990). Qualitative Evaluation and Research Methods (2nd ed.). Newbury Park, CA: Sage Publications.

Peters, M. A., Marginson, S., \& Murphy, P. (2009). Creativity and the global knowledge economy. New York: Peter Lang Publishing Inc.

Pistone, N. (2000). Envisioning arts assessment: A process guide for assessing arts education in school districts and states. Retrieved June 2, 2008, from http://www.aep-arts.org/files/evaluation/EnvArtsAssess.pdf

Polkinghorne, D. E. (1995). Narrative configuration in qualitative analysis. In H. A. R. Wisniewski (Ed.), Life history and narrative (pp. 5-24). London: Falmer Press.

Rendle-Short, F. (1999). On the edge. Art Monthly, 126, 15.

Ross, M., Randor, H., Mitchell, S., \& Bierton, C. (1993). Assessing achievement in the arts. Philadelphia: Open University Press.

Scott-Murphy, L. (2004). Toward a model of theatrical curation. Paper presented to the Creative Connections Symposium, Arts Research Network, September 2004.

Smith, R. A., \& Simpson, A. (Eds.). (1991). Aesthetics and arts education. Champaign, Ill.: University of Illinois Press.

Snyder, B. R. (1971). The hidden curriculum. New York: Knopf.

Sternberg, R. J., Kaufman, J. C., \& Pretz, J. E. (2002). The creativity conundrum. New York: Psychology Press.

Sylvester, D. (1999). Curator and critic London. Sydney Morning Herald. Retrieved December 21, 2011, from http://www. hsc.csu.edu.au/visual_arts/content/.../MDOC3Roleofcurator.html

Taylor, P. (2006). Assessment in arts education. Portsmouth, NH: Heinemann.

Thomas, D. (1999). Being a curator. Art Monthly, 123, 4.

Tomlinson, C. A. (2001). Grading for success. Educational Leadership, 58(6), 12-15.

Wiersma, W., \& Jurs, S. G. (2005). Research Methods in Education (8th ed.). Boston: Pearson, Allyn and Bacon.

Willoughby, M., Feifs, H., Baenen, N., \& Grimes, E. (1995). Behind the scenes: Measuring student progress in the arts and beyond. Raleigh, N.C.: Evaluation and Research Dept., Wake County Public School System. 